\title{
Numerical modeling transient flow in plastic pipes
}

\section{N. ACHAK ${ }^{1}$, B. BAHRAR $^{2}$, K. GUERAOUI $^{1}$}

\author{
${ }^{1}$ Team of Modeling and simulation of Mechanical and Energetic, Faculty of sciences, \\ Mohammed V University, Rabat, Morocco. \\ achaknawal3@gmail.com \\ 2 Team of Fluid Mechanics \& Environment, ENSET Mohammedia, Condensed Matter Physics Laboratory, \\ FST Mohammedia, Hassan II University Casablanca, Morocco. \\ bahrarb@yahoo.fr
}

\begin{abstract}
We present a numerical code for calculating transient flow in plastic pipes, especially in the polyethylene pipe, to analysis effect of material viscoelasticity on water hammer phenomena. The set partial differential equations to be solved is obtained using conservation laws and behavior for the fluid and the pipe wall, associated with constitutive equations of the two media, and relationships compatibility of interfaces on velocities and stresses. A global digital processing is achieved using the method of characteristics. The results obtained are in good agreement with those found in the literature.
\end{abstract}

Keywords: hydraulic transient, plastic pipes, polyethylene, water-hammer, methods of characteristics, numerical processing.

\section{Introduction}

Water hammer, or hydraulic transient, refers to pressure fluctuations caused by a sudden increase or decrease in flow velocity. In this way, many theoretical and experimental studies have, usually, conducted assuming linear elastic behaviour of the pipe wall without mass [1, $2,3]$, that is means, time scales of inertia of pipe wall is negligible. In view of industry practice, classical waterhammer studies are interested in estimating the pressure caused by water hammer. This can, under certain conditions, have disadvantages on pipes conveying fluid, and also, it can be useful for generating energy. In the field of plastic materials, the pioneering studies appear to be those of Tison in 1958 [4], who had noticed the influence of viscoelasticity on the transient flow behavior associated with the valve opening. Include, also, the work of Blanchard and Rieutord [5, 6, 7] and later experimental verification carried out by Güney et al [7]. More recently, Soares et al. [8] and Karmat et al. [9] have conducted similar studies.

The interest of this study is the use of increasingly growing plastic tubes (PVC, polyethylene,...) in different industries and service life compared to traditional piping materials. This leads us to examine the influence of the viscoelastic behavior of these materials on hydraulic transient flows. A comparison and validation of our code is done with the measurement results conducted by Güney [8], at INSA Lyon

\section{Assumptions and basic equations}

The basic equations are derived from the classical laws of conservation of mass, momentum for the fluid and the pipe wall in the case of isentropic transformations. We assume also that the fluid is barotropic Newtonian and in the expression of the viscous stress, the longitudinal velocity gradients are negligible compared to transverse gradients. The material of the pipe wall behaves like linear elastic or viscoelastic, isotropic, Kelvin Voigt type $[10,11]$. Geometrically, the pipe is assumed to be cylindrical horizontal, the cylindrical coordinates are $(\mathrm{x}, \mathrm{r}, \theta)$. One of its end is rigidly attached to a reservoir upstream, which imposes a constant pressure and the other is on a fixed support and including an operating valve. The flow is axisymmetric and longitudinal gradients of velocity are assumed to be small compared to transverse gradients.

Given these assumptions, the averaged equations of the flow in a cross section of pipe can be written in traditionally a one-dimensional formulation, reflecting the relations of conservation of mass and momentum averaged over a section of a cross section, as hyperbolic system that is suitable for characteristic methods: In summary, the system of equations to be solved is:

$$
\begin{gathered}
\frac{1}{\rho_{f}} \frac{d P}{d t}+a^{2} \frac{\partial V}{\partial x}+2 a^{2} \frac{d \varepsilon^{r}}{d t}=0 \\
\rho_{f} \frac{d V}{d t}+\frac{\partial P}{\partial x}+\rho_{f} g \frac{\partial z}{\partial x}-\frac{4 \tau_{f}}{D}=0 \\
a=\left(\rho_{f}\left(1 / \kappa+\alpha D_{m} J(0) / e\right)\right)^{-1 / 2}
\end{gathered}
$$

$\alpha$ : parameter characterizing the type of anchoring the pipe and which, in the case of a pipe anchored longitudinally, is written. [2]:

for strain retarded creep, in linear viscoelasticity.

The shear stress $\tau_{f}=\tau_{q}+\tau_{u},[12,13,14]$, is composed of the quasi-stationary part $\tau_{q}$ related to the quasi-steady friction $\lambda$ and depending on the flow regime and the relative roughness of the pipe which in the case of turbulent flow, is derived from the Colebrook equation: 


$$
\frac{1}{\sqrt{\lambda}}=-2 \log _{10}\left(\frac{2,51}{\operatorname{Re} \sqrt{\lambda}}+\frac{(\varepsilon / D)}{3,71}\right)
$$

Where $\mathrm{R}_{\mathrm{e}}$ is the Reynolds number; $\varepsilon$ is the roughness of the pipe wall. The unsteady part $\tau_{\mathrm{u}}$ linked to the convolution product is:

$$
\tau_{u}=\frac{4 \mu}{D S} \int_{0}^{t} W\left(t-t^{\prime}\right) \frac{\partial V\left(t^{\prime}\right)}{\partial t^{\prime}} d t^{\prime}
$$

$\mu$ is the dynamic viscosity of water, $W$ the weighting function related to Zielke's model [12].

\section{Modelling of the creep function}

The creep function can be discrezed as:

$$
J(t)=J_{0}+\sum_{i=1}^{n} J_{i}\left(1-\exp \left(-t / \tau_{i}\right)\right)
$$

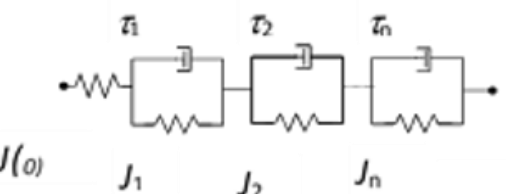

It's corresponding to a Kelvin-Voigt model with a spring module in parallel with the viscous dampers $\eta_{i}$, leading to a relaxation time $\tau_{i}=\eta_{i} / E_{i}, J_{0}$ representing the instantaneous compliance, $J(0)$, the inverse of the instantaneous elastic modulus $\mathrm{E}(0)$. If we set, $\varepsilon^{r}=0$, that is $J_{i}=0$, or, if $\tau_{i}=\infty$,we find a classical elastic case.

\section{Initial and boundary conditions}

The initial conditions are those for steady flow and the balance for the pipe wall. The boundary conditions are in addition to the pressure imposed by the tank on the upstream and the instantaneous closing of a free valve on the downstream, the conditions of fluid-conduit interfaces requiring, in viscous flow, equal velocities and stresses as well as:

$$
P(0, t)=\rho g H_{0},
$$

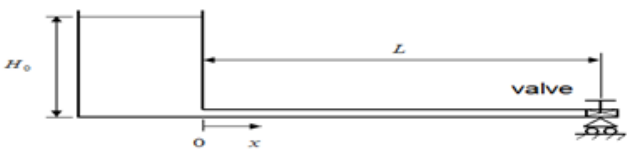

Fig. 1: diagram of the system studied

\section{Numerical solution}

The numerical solution of hyperbolic systems (1) and (2) associated to initial and boundary conditions can easily be obtained by the usual method of characteristics $[15$, $16]$.

\section{Application and results}

In this application, we consider steady-state flow value $\mathrm{V} 0=0.5 \mathrm{~m} / \mathrm{s}$. The flow is in the horizontal pipe anchored to the upstream to a tank filled with water and of height $\mathrm{H}$, ending at the downstream to a valve that closes abruptly. The parameters of the fluid and the pipe are summarized in table I:

TABLE I

PARAMETER VALUES OF FLOW

\begin{tabular}{lc}
\multicolumn{1}{c}{ Components } & \\
\hline \hline & values \\
\hline Tank height $H_{0}(\mathrm{~m})$ & 0.55 \\
Internal pipe diameter $(\mathrm{mm})$ & 50 \\
Length of pipe $(\mathrm{m})$ & 43.1 \\
Thickness of the pipe $(\mathrm{mm})$ & 4.2 \\
Dynamic viscosity of water $($ Pa.s $)$ & $1.11 \times 10^{-3}$ \\
Poisson's ratio & 0.43 \\
Bulk modulus of water $(\mathrm{GPa})$ & 2.2 \\
Density of water $\left(\mathrm{Kg} / \mathrm{m}^{3}\right)$ & 1000 \\
\end{tabular}

Table II

EXPERIMENTAL VALUES OF COMPLIANCES AND RELAXATION TIMES FOR DIFFERENT TEMPERATURE

\begin{tabular}{|c|l|l|l|l|l|l|}
\hline$\left.{ }^{\circ} \mathrm{C}\right)$ & $\begin{array}{l}J_{0} \times 10^{-9} \\
(\mathrm{~Pa})^{-1}\end{array}$ & $\begin{array}{l}J_{1} \times 10^{-9} \\
(\mathrm{~Pa})^{-1}\end{array}$ & $\begin{array}{l}J_{2} \times 10^{-9} \\
(\mathrm{~Pa})^{-1}\end{array}$ & $\begin{array}{l}J_{3} \times 10^{-9} \\
(\mathrm{~Pa})^{-1}\end{array}$ & $\tau_{1}(s)$ & $\tau_{2}(s)$ \\
\hline 13.8 & 1.144 & 0.516 & 0.637 & 0.871 & $0.56 \times 10^{-4}$ & 0.0166 \\
\hline 25 & 1.542 & 0.754 & 1.046 & 1.237 & $0.89 \times 10^{-4}$ & 0.0222 \\
\hline 31 & 1.791 & 1.009 & 1.397 & 1.628 & $1.15 \times 10^{-4}$ & 0.0221 \\
\hline 35 & 1.995 & 1.235 & 1.797 & 2.349 & $1.38 \times 10^{-4}$ & 0.0265 \\
\hline 38.5 & 2.239 & 1.479 & 2.097 & 3.570 & $1.24 \times 10^{-4}$ & 0.0347 \\
\hline
\end{tabular}

We conduct the calculation in the case of a polyethylene pipe tested at the Laboratory of Fluid Mechanics at INSA Lyon [7] and with experimental records are shown as a function of temperature in figure 3 . This study shows that the viscoelastic behaviour of the pipe wall is even more pronounced as the temperature is high.

At low temperatures, little change explains that one can admit behaviour substantially elastic. But when the temperature rises, the effect of viscoelasticity is dominant and must be taken into account in the calculations.

In the following, we consider an application for both temperatures $25{ }^{\circ} \mathrm{C}, \quad 31{ }^{\circ} \mathrm{C}$ and $38.5{ }^{\circ} \mathrm{C}$ for the corresponding values in the table above. The results presented represent the evolution of the average pressure in pipe versus time for different values of the polyethylene temperature. It shows that the effect of the viscoelasticity of the material becomes greater with increasing its temperature. 


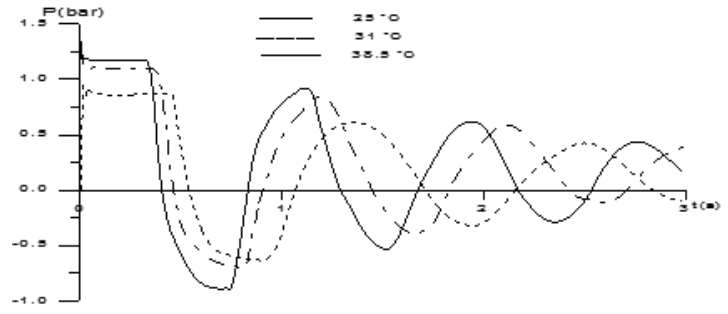

Fig. 2 - Effect of the viscoelasticity with temperature

\section{Conclusion}

This study highlighted, in the case of plastic materials, such as polyethylene, the damping effect of pipe viscoelasticity on transient pipe flow. This is in addition to the viscosity of the fluid. The damping of pressure intensity becomes more prominent with the temperature. Il can be an effective tool for controlling the pressure in a hydraulic system by adding a section of pipe in plastic material. This study can be, also, under assumptions, adapted arterial conducts.

\section{References}

[1] Y. Joukowsky, Ûber der, hydraulischen Stoss in Wasserleitungen [Over the hydraulic shock in water pipes]. Mémoires de l'Académie Impériale de St. Petersbourg, Bd. IX, N.5, 1900.

[2] E. B. Wylie, V. L. Streeter, Fluid Transients. New York: Mac Graw-Hill, 1978.

[3] L. Bergeron, Waterhammer in Hydraulics and Waves Surges in Electricity, John Wiley and Sons, Inc., New York, 1961.

[4] G. Tison, Le mouvement non permanent succédant à l'ouverture d'une vanne sur une conduite en polyéthylène, Becetel, communication $\mathrm{N}^{\circ} 3$, Université de Gand, 1958.

[5] E. Rieutord and A. Blanchard, Écoulement non permanent en conduite viscoélastique - coup de bélier, Journal of Hydraulic research, V17(3), 1979.

[6] M. Gally, M. Güney, E. Rieutord, An Investigation of Pressure Transients in Viscoelastic Pipes, J.Fluids Eng V101(4), pp 495-499, 1979.

[7] MS. Güney Waterhammer in visco-elastic pipes where cross-section parameters are timedependent. Proceedings of the 4th International onference on ressure urges, $\mathrm{H} \mathrm{A}$, ranfield, UK: 189-204, 1983.

[8] AK Soares, DIC Covas, LFR Reis, Analysis of $P V C$ pipe-wall viscoelasticity during waterhammer. ASCE Journal of Hydraulic Engineering 134(9): 1389-1394, 2008.

[9] A. Keramat, AS.Tijsseling, Q. Hou, A. Ahmadi Fluid-structure interaction with pipe-wall viscoelasticity during waterhammer. Journal of Fluids and Structures 28: 434-455, 2012.

[10]J. Mandel, Cours de mécanique des milieux continus, Gauthier-Villars, Paris, Vol. 2, Annexe XXI, 1966.

[11]R.M. Christensen, Theory of viscoelasticity an introduction, Academic Press. 1971.

[12]W. Zielke, Frequency Dependent Friction in Transient Pipe Flow, ASME, Journal of Basic Engineering, V90(1), 1968.

[13] J. Vítkovský, M.L. Stephens, A. Bergant, M. Lambert, A.R. Simpson, Efficient and accurate calculation of Zielke and Vardy-Brown unsteady friction in pipe transients, Proc. 9th International Conference on Pressure Surges (Ed. Murray, S.J.), BHR Group, Chester, UK, Vol. 2, pp. 405-419. , 2004

[14]A.E. Vardy, J.M.B. Brown, Transient Turbulent Friction in fully rough Pipe Flows. Journal of Sound and Vibration, V270(1-2), pp 233-257, 2004.

[15] D.E. Goldberg and E.B. Wylie, Characteristics Method Using Time-Line Interpolation, ASCE Journal of Hydraulic Division, V109(5), 1983.

[16] A.R. Courant and D. Hilbert, Method of Mathematical Physics, Vol. 1 and 2, Interscience Publishers, N.Y., 1962. 